\title{
ROMANTIKA KESEDERHANAAN DALAM NOVEL HUJAN BULAN JUNI KARYA SAPARDI DJOKO DAMONO: KAJIAN STILISTIKA
}

\author{
Dhea Rizka Noor Aliefta ${ }^{\bowtie}$, Mulyono, dan Maharani Intan Andalas
}

Jurusan Bahasa dan Sastra Indonesia, Fakultas Bahasa dan Seni, Universitas Negeri Semarang, Indonesia

\section{Info Artikel}

Sejarah Artikel:

Diterima Juni 2018

Disetujui Agustus 2018

Dipublikasikan November 2018

\section{Keywords.}

romantic of simplicity, stylistic, language style

\begin{abstract}
Abstrak
Sapardi adalah seorang sastrawan yang memiliki nilai keromantisan yang tinggi. Dalam novelnya yang berjudul Hujan Bulan Juni, menggambarkan romantika kesederhanaan mengenai konflik liku-liku kehidupan percintaan yang dialami kedua tokoh yang dibantu tokoh-tokoh lainnya, konflik tersebut dapat diteliti menggunakan gaya bahasa melalui pendekatan stilistika dengan metode deskriptif kualitatif. Penelitian ini bertujuan untuk mengetahui romantika kesederhanaan melalui gaya bahasa dalam novel tersebut serta untuk mengetahui fungsi gaya bahasa yang mengungkapkan keseluruhan maknanya. Novel Hujan Bulan Juni merupakan novel serius, karena menggambarkan perjalanan kehidupan dan percintaan tokoh. Merupakan novel romansa, karena pengarang menggunakan bahasabahasa kiasan yang berbentuk narasi bersifat puitis. Gaya bahasa yang mengungkapkan romantika kesederhanaan terdapat empat gaya kalimat, empat gaya kata, bahasa figuratif dengan delapan permajasan, idiom, dan peribahasa, tiga citraan, dan sisipan sajak berfungsi sebagai penekanan antar tokoh, mewujudkan peristiwa, menciptakan makna, menghidupkan objek, suasana, dan alur.
\end{abstract}

\begin{abstract}
Sapardi is a person who has high of romace value. In his novel, Hujan Bulan Juni, describe the romance of the simplicity of the conflict between the twists and turns of the love life experienced by the two figures assisted by other figures, the conflict can be examined using the style of language through a stylistic appoarch with qualitative descriptive method. This study aims to determine the romance of simplicity through the style of language in the novel as well as to know the function of language style the expresses the whole meaning. Hujan Bulan Juni novel is a serious novel, because it describes of journey of life and romance of a character. It is a romance novel, because the author uses figurative language in the form of narrative is poetic. The style of language that reveals romantic simplicity lies in four sentence styles, four word styles, figurative languages with eight rhimes, idioms, and proverbs, three images, and poet inserts functioning as intercultural emphases, realizing events, creating meaning, animating objects, plot.
\end{abstract}

(C) 2018 Universitas Negeri Semarang

\footnotetext{
Alamat korespondensi:

Gedung B1 Lantai 1 FBS Unnes

Kampus Sekaran, Gunungpati, Semarang, 50229

E-mail: dhea22@gmail.com
}

ISSN 2252-6315 


\section{PENDAHULUAN}

Bahasa merupakan sarana yang digunakan pengarang untuk menyampaikan buah pikiran dan imajinasinya dalam proses penciptaan karya sastra (Supriyanto, 2011:1). Dengan demikian, bahasa merupakan sarana yang penting dalam sebuah karya sastra. Bahasa digunakan pengarang sebagai alat untuk mengungkapkan fenomena kehidupan yang dilihatnya ke dalam cerita.

Pengarang menggambarkan fenomena kehidupan melalui konflik yang dialami oleh tokoh-tokoh dalam karya sastra. Hal tersebut, berarti karya sastra menggambarkan mengenai romantika. Dalam KBBI edisi Keempat (2008), romantika berarti liku-liku atau seluk beluk kehidupan. Karya sastra menggambarkan romantika mengenai liku-liku atau perjuangan kehidupan seseorang yang kemudian dituangkan melalui bahasa.

Setiap pengarang memiliki gaya bahasa yang berbeda-beda. Salah satunya, Sapardi Djoko Damono menggunakan gaya bahasa dengan sederhana, tetapi makna yang terkandung dalam bahasa tersebut memiliki nilai keindahan pada karya sastra yang diciptakannya. Menurut Sapardi, karya sastra berupa puisi dan cerita sama saja. Hal ini dimungkinkan karena adanya esensi yang sama, bahwa sebenarnya ditekankan pada jiwanya bukan bentuk karya sastra tersebut (Soemanto dalam Sarumpaet, 2010; 77).

Novel Hujan Bulan Juni karya Sapardi Djoko Damono ini merupakan novel serius bergenre novel romansa. Novel bersifat realistis, sedangkan romansa bersifat puitis dan epik (Nurgiyantoro, 2012: 15). Novel bersifat realistis, karena merupakan gambaran dari kehidupan dan prilaku yang nyata dari zaman ketika novel tersebut diciptakan, sedangkan romansa, ditulis dalam bahasa yang agung dan diperindah, menggambarkan apa yang tidak pernah terjadi dan tidak mungkin terjadi (Wellek\&Warren, 1989: 285). Novel Hujan Bulan Juni merupakan novel serius, karena menggambarkan perjalanan kehidupan dan percintaan tokoh. Novel tersebut juga merupakan novel romansa, karena pengarang menggunakan bahasa-bahasa kiasan yang diciptakan berbentuk narasi namun bersifat puitis. Sapardi tidak pernah terlepas dari puisi, sehingga dalam novel Hujan Bulan Juni disisipkan puisi-puisi kecil.

Novel Hujan Bulan Juni menggambarkan romantika kesederhanaan mengenai konflik liku-liku kehidupan percintaan yang dialami kedua tokoh dengan dibantu tokoh-tokoh lainnya, konflik tersebut dapat diteliti menggunakan gaya bahasa dalam kajian stilistika.

Beberapa penelitian gaya bahasa yang sudah dilakukan pada karya Sapardi, umumnya menganalisis puisi sebagai objek penelitian, seperti pada kumpulan puisi Hujan Bulan Juni, yang berjudul "Gaya Bahasa Kumpulan Puisi Hujan Bulan Juni karya Sapardi Djoko Damono dan Implikasinya terhadap Pembelajaran Sastra di Sekolah Menengah Pertama" karya Tri Windusari (2014). Penelitian pada novel Hujan Bulan Juni juga sudah dilakukan, yaitu "Religiositas dalam Novel Hujan Bulan Juni Karya Sapardi Djoko Damono dan Rancangan Pembelajarannya di Sekolah Menengah Atas (SMA)" karya Nur Mila (2016) yang membahas mengenai religiositas yang mengangkat perkawinan lintas agama antara kedua tokoh dalam novel tersebut dan "Alur Dalam Novel Hujan Bulan Juni karya Sapardi Djoko Damono dan Rancangan Pembelajaran di SMA" karya Nadya Oktami (2016) yang membahas mengenai alur yang digunakan Sapardi dalam novel tersebut.

Novel Hujan Bulan Juni menggambarkan romantika kesederhanaan mengenai konflik liku-liku kehidupan percintaan yang dialami kedua tokoh dengan dibantu tokoh-tokoh lainnya, konflik tersebut dapat diteliti menggunakan gaya bahasa dalam kajian stilistika. Sejauh pengetahuan peneliti, novel Hujan Bulan Juni belum diteliti menggunakan kajian stilistika terutama romantika kesederhanaannya.

Berdasarkan latar belakang masalah di atas, masalah yang dibahas dalam penelitian ini adalah sebagai berikut (1) bagaimana gaya bahasa yang mengungkapkan romantika kesederhanaan dalam novel Hujan Bulan Juni karya Sapardi Djoko Damono (2) bagaimana fungsi pemakaian gaya bahasa untuk mengungkapkan keseluruhan makna dalam novel Hujan Bulan Juni.

Berdasarkan rumusan masalah di atas, tujuan penelitian ini adalah sebagai berikut (1) mendeskripsikan penggunaan gaya bahasa yang mengungkapkan romantika kesederhanaan pada novel Hujan Bulan Juni (2) mendeskripsikan fungsi pemakaian gaya bahasa untuk mendukung keseluruhan makna pada novel Hujan Bulan Juni.

\section{METODE PENELITIAN}

Penelitian ini menggunakan pendekatan stilistika dengan metode deskriptif kualitatif. Pendekatan stilistika menjelaskan mengenai 
gaya bahasa yang digunakan pengarang dalam karya sastra tersebut, sedangkan metode deskriptif kualitatif adalah metode yang dijelaskan melalui kata, frasa, atau kalimat yang terdapat dalam objek penelitian.

Data penelitian dalam penelitian ini berupa data kata, frasa, maupun kalimat yang berisi tentang gaya bahasa yang terdapat pada konflik romantika kesederhanaan tokoh pada novel Hujan Bulan Juni karya Sapardi Djoko Damono. Dengan demikian, pembahasan dalam penelitian ini berisi kutipan-kutipan data untuk memberikan penyajian pembahasan untuk penunjang kajian tersebut. Sumber data dalam penelitian ini adalah novel Hujan Bulan Juni karya Sapardi Djoko Damono yang diterbitkan PT. Gramedia Pustaka Utama; Jakarta pada tahun 2015 cetakan pertama dengan tebal buku 135 halaman.

Teknik pengumpulan data dalam penelitian ini menggunakan metode baca catat dan kepustakaan. Teknik baca catat adalah metode yang digunakan untuk mengumpulkan data dengan membaca seluruh isi novel Hujan Bulan Juni karya Sapardi Djoko Damono secara berulang-ulang kemudian dicari dan dicatat halhal pokok yang berhubungan dengan gaya bahasa yang mengungkapkan romantika kesederhanaan untuk mendapatkan data yang akurat. Teknik kepustakaan adalah teknik yang digunakan untuk mengumpulkan data dengan menjelaskan romantika kesederhanaan melalui konsep-konsep stilistika dalam novel Hujan Bulan Juni.

\section{HASIL PENELITIAN}

Romantika kesederhanaan merupakan liku-liku atau seluk beluk kehidupan yang digambarkan pengarang dengan bahasa yang sederhana, tetapi memiliki makna yang sangat mendalam. Romantika kesederhanaan dapat tercipta apabila pengarang menggunakan bahasa yang indah untuk membuai pembaca sehingga menimbulkan kesan estetis. Dalam novel tersebut, ditemukan beberapa gaya bahasa yang mengungkapkan romantika kesederhanaan yaitu gaya kalimat, gaya kata, bahasa figuratif, dan citraan, sisipan sajak yang membantu menghidupkan alur dan suasana.

Gaya kalimat merupakan struktur kalimat yang terbentuk secara gramatikal sesuai dengan karakteristik pengarang. Dalam novel tersebut, ditemukan empat gaya kalimat yang mengungkapkan romantika kesederhanaan yaitu gaya kalimat inversi, gaya kalimat elipsis, gaya kalimat repetisi, dan gaya kalimat paralelisme. Salah satu kutipan gaya kalimat yang mengungkapkan romantika kesederhanaan yaitu,

Maunya Sarwono, Pingkan hanya sama dia. Bodoh ya gak apa-apa, kan? Aku tidak waras lagi, "kali, "katanya kepada dirinya sendiri (hlm. 92).

Kutipan di atas merupakan kalimat inversi karena kalimat "maunya Sarwono" merupakan predikat-subjek. Penggunaan kalimat inversi dalam kutipan ini merupakan romantika kesederhanaan, karena lebih menekankan pada 'kemauan atau keinginan' Sarwono bahwa dia hanya ingin Pingkan menjadi miliknya, tidak boleh ada yang memiliki Pingkan selain Sarwono. Merupakan romantika kesederhanaan, karena penggunaan predikat-subjek yang sesuai untuk menyatakan keinginan Sarwono memiliki Pingkan seutuhnya digambarkan menggunakan kalimat yang sederhana. Apabila pada predikat-subjek "maunya Sarwono" diganti menjadi "keinginan Sarwono" atau "Sarwono ingin", maka tidak ada penekanan pada kalimat inversi tersebut dan nilai estetisnya berkurang.

Gaya kata yang ditemukan dalam novel Hujan Bulan Juni terdapat gaya kata konotatif, gaya kata konkret, gaya kata sapaan, dan gaya kata daerah. Penggunaan gaya kata daerah dalam novel tersebut lebih menonjol karena untuk menghidupkan latar tempat, berikut kutipannya.

"Karepku ngene lho, Sar. Kowe rak bocah ontanganting, yen milih bojo sing ngati-ati supaya tembe mbrurine ora ngrusuhi aku lan ibumu," kata ayahnya (hlm. 90).

Maksud dari kutipan di atas, ialah keinginan Ayah Sarwono, bahwa Sarwono itu anak satu-satunya. Jika memilih pasangan harus hati-hati agar nanti ketika berumah tangga tidak menyusahkan ayah dan ibunya. Perhatian ayah Sarwono merupakan bentuk romantika kesederhanaan yang digambarkan dengan bahasa Jawa sebagai amanat untuk Sarwono.

Terdapat tiga penggunaan bahasa figuratif dalam novel Hujan Bulan Juni, yaitu permajasan, idiom, dan peribahasa. Sapardi menggunakan delapan majas untuk mengungkapkan romantika kesederhanaan, yaitu majas satire, majas personifikasi, majas hiperbola, majas epitet, majas ironi, majas simile, majas sarkasme, dan majas metafora. Salah satu contoh majas yang mengungkapkan romantika kesederhanaan, yaitu majas ironi. Kutipannya sebagai berikut.

P: Cilakak. Kemarin sepupuku bilang, kalau kamu dicium Buto Galak dari Jawa itu nanti anakmu disuruh salat tho. 
S: daripada nunggu anak kita lahir, kamu aja yang ikut salat. Mau? (hlm. 40).

Kutipan di atas, termasuk majas ironi karena sindiran yang merupakan suatu acuan menyatakan sesuatu dengan makna atau maksud yang berlainan. Pingkan membahas mengenai sepupunya yang mengatakan jika ia menikah dengan Sarwono anaknya akan ikut agama Sarwono dengan melalui sindiran "kalau kamu dicium Buto Galak dari Jawa itu nanti anakmu disuruh salat tho."

Dalam kutipan di atas, Sarwono pun juga melakukan sindiran dengan mengajak Pingkan untuk salat, artinya agar Pingkan saja yang ikut keyakinan Sarwono. Romantika kesederhanaannya, terlihat pada percakapan mereka melalui sindiran-sindiran yang mereka lakukan satu sama lain melalui WhatsApp dengan struktur kalimat yang digunakan pengarang. Sebenarnya mereka masih bingung dengan hubungan mereka yang terhalang perbedaan agama, hanya saja mereka saling meyakinkan kalau hubungan mereka mampu untuk dilanjutkan sampai jenjang pernikahan.

Dalam novel Hujan Bulan Juni terdapat tiga citraan, yaitu citraan pendengaran, citraan penglihatan, dan citraan perabaan. Salah satu kutipan yang menyatakan citraan untuk mengungkapkan romantika kesederhanaan yaitu,

Jawaban Pak Pelenkahu dulu itu terdengar olehnya kembali seperti sebuah nyanyian purba yang tunggal nadanya, yang bunyinya mirip denting gelas bening kosong kalau tersentuh sendok teh ketika Pingkan sedang sarapan (hlm. 56).

Dari kutipan di atas, merupakan citraan pendengaran. Pingkan kembali mendengar suara Pak Pelenkahu yang sangat nyaring ditelinganya. Pak Pelenkahu adalah ayah Pingkan yang sudah meninggal dan terlihat pada kutipan di atas Pingkan sedang merindukan ayahnya sehingga teringat omongan ayahnya dan terdengar sangat nyaring di telinganya.

Terdapat sisipan sajak dalam novel Hujan Bulan Juni yang berfungsi untuk menghidupkan suasana. Sajak-sajak tersebut membantu jalannya alur dalam penggambaran romantika kesederhanaan karena menggambarkan perasaan Sarwono dan Pingkan satu sama lain.

Berdasarkan penelitian di atas, gaya bahasa dalam novel Hujan Bulan Juni karya Sapardi Djoko Damono terdapat gaya kalimat, gaya kata, bahasa figuratif, dan citraan. Gaya kalimat yang digunakan pengarang yaitu kalimat inversi, kalimat elipsis, kalimat repetisi, dan kalimat paralelisme. Fungsi gaya kalimat tersebut sebagai penekanan dalam mengungkapkan romantika kesederhanaan tokoh, baik tokoh Sarwono dengan Pingkan, Sarwono dengan kedua orangtuanya, maupun Sarwono dengan Ibu Pelenkahu. Gaya kalimat yang digunakan pengarang sangat sederhana, namun keromantisan setiap kalimatnya atau setiap kutipannya membawa pembaca masuk kedalam suasana cerita. Gaya kata yang digunakan dalam novel ini terdapat kata konotatif, kata konkret, kata sapaan diri, kata daerah. Gaya kata tersebut memiliki fungsi untuk mengungkapkan romantika kesederhanaan dalam mewujudkan peristiwa. Kemudian juga terdapat bahasa figuratif yang memiliki fungsi menciptakan makna, sedangkan citraan memiliki fungsi untuk lebih menghidupkan objek yang digambarkan. Terdapat sisipan sajak untuk mendukung dalam pemaknaan romantika kesederhanaan, yang fungsinya sebagai mendukung menghidupkan suasana mengenai perasaan antara tokoh Sarwono dan Pingkan yang kemudian tergambar secara lebih nyata dan semakin kuat. Dalam sisipan-sisipan sajak tersebut di dalamnya juga terdapat gaya bahasa yang digunakan untuk menambah nilai estetis.

Yang lebih menonjol dalam novel ini adalah penggunaan gaya bahasa daerah, fungsi penggunaan bahasa daerah tersebut untuk menghidupkan latar dalam novel ini, sehingga pembaca memiliki gambaran yang nyata pada tokoh Sarwono dan keluarga Hadi. Penggunaan bahasa Manado pun juga terdapat dalam novel ini untuk menghidupkan latar dan tokoh Pingkan serta keluarga Pelenkahu.

Romantika

kesederhanaan dimaksudkan sebagai sebuah peristiwa atau perjalanan kehidupan antar tokoh yang mewujud melalui pilihan-pilihan kata sederhana yang digunakan dalam novel Hujan Bulan Juni. Gaya bahasa yang sederhana tersebut sebenarnya menciptakan makna romantika yang tidak sederhana.

\section{SIMPULAN}

Dalam novel Hujan Bulan Juni karya Sapardi Djoko Damono, terdapat beberapa gaya bahasa yang mengungkapkan romantika kesederhanaan. Romantika kesederhanaan dimaksudkan sebagai sebuah peristiwa atau perjalanan kehidupan tokoh yang ada dalam novel Hujan Bulan Juni yang mewujud melalui pilihan-pilihan kata yang digunakan dalam novel tersebut. Gaya bahasa yang sederhana tersebut sebenarnya menciptakan makna 
romantika yang tidak sederhana. Terdapat empat gaya bahasa yang digunakan dalam novel tersebut yang mengandung romantika kesederhanaan yaitu gaya kalimat, gaya kata, bahasa figuratif, dan citraan. (1) Gaya kalimat yang terdapat dalam novel Hujan Bulan Juni yaitu, kalimat inversi, kalimat elipsis, kalimat repetisi, dan kalimat paralelisme; (2) Terdapat empat gaya kata, yaitu kata konotatif, kata konkret, kata sapaan, dan kata daerah; (3) Bahasa figuratif terdiri atas delapan permajasan, idiom, dan peribahasa. Delapan permajasan yang terdapat dalam novel ini, yaitu majas satire, majas personifikasi, majas hiperbola, majas epitet, majas ironi, majas simile, majas sarkasme, dan majas metafora; (4) Terdapat citraan yang mengungkapkan romantika kesederhanaan, yaitu citraan pendengaran, citraan penglihatan, dan citraan perabaan; Selain itu, (5) terdapat faktor pendukung lainnya dalam pengungkapan romantika kesederhanaan, yaitu sisipan sajak-sajak dalam novel Hujan Bulan Juni.

Fungsi pemakaian gaya bahasa dalam novel Hujan Bulan Juni karya Sapardi Djoko Damono yang mendukung keseluruhan makna terdapat pada gaya kalimat, gaya kata, bahasa figuratif, dan citraan. Gaya kalimat berfungsi sebagai penekanan dalam mengungkapkan romantika kesederhanaan tokoh. Gaya kata yang digunakan dalam novel tersebut memiliki fungsi untuk mengungkapkan romantika kesederhanaan dalam mewujudkan peristiwa. Dalam novel tersebut, juga terdapat bahasa figuratif yang memiliki fungsi menciptakan makna, sedangkan citraan memiliki fungsi untuk lebih menghidupkan objek yang digambarkan. Terdapat sisipan sajak dalam novel tersebut untuk menghidupkan suasana dengan lebih menonjolkan perasaan antara tokoh Sarwono dan Pingkan. Yang lebih menonjol dalam novel tersebut, penggunaan gaya bahasa daerah Jawa dan Manado, berfungsi untuk menghidupkan latar dalam novel ini. Fungsi pemakaian gaya bahasa yang memiliki peran penting dalam mendukung jalannya alur.

\section{DAFTAR PUSTAKA}

Damono, Sapardi Djoko. 2015. Hujan Bulan Juni. Jakarta: PT. Gramedia Tustaka Utama.

Departemen Pendidikan Nasional. 2008. Kamus Besar Bahasa Indonesia Edisi Keempat. Jakarta. PT Gramedia Pustaka Utama.

Mila, Nur. 2016. "Religiositas dalam Novel Hujan Bulan Juni Karya Sapardi Djoko
Damono dan Rancangan Pembelajarannya di Sekolah Menengah Atas (SMA)." Skripsi. Universitas Lampung.

Nurgiyantoro, Burhan. 2012. Teori Pengkajian Fiksi.Yogyakarta: Gadjah Mada University Press.

Oktami, Nadya. 2016. "Alur Dalam Novel Hujan Bulan Juni Karya Sapardi Djoko Damono Dan Rancangan Pembelajaran di SMA". Skripsi. Universitas Lampung.

Sarumpaet, Riris K.Toha\&Melani Budianta. (Ed). 2010. Bakdi Soemanto "Membaca Sapardi: Teks-Teks yang Bersilangan". Jakarta: Yayasan Pustaka Obor.

Sutrisno, Mudji dan Christ Verhaak SJ. 1993. Estetika Filsafat Keindahan. Yogyakarta: Penerbit Kanisius.

Wellek, Rene dan Austin Warren. 1989. Teori Kesusastraan. Jakarta: PT Gramedia.

Windusari, Tri. 2014. "Gaya Bahasa Kumpulan Puisi Hujan Bulan Juni Karya Sapardi Djoko Damono Dan Implikasinya Terhadap Pembelajaran Sastra Di Sekolah Menengah Pertama." Skripsi. Universitas Islam Negeri Syarif Hidayatullah Jakarta. 